\title{
Edgar Morin e sua trilogia voltada ao sistema educacional
}

\author{
Michelle Padilha Batistella* \\ Ettiène Guérios **
}

\section{Resumo}

Trata-se de uma pesquisa qualitativa, descritiva-analítica, na modalidade bibliográfica de natureza teórica. Tem como objetivo oferecer aos professores da Educação Básica e aos professores formadores uma sistematização de conhecimentos acerca da complexidade e do pensamento complexo que pode auxiliá-los em suas práticas pedagógicas. $\mathrm{O}$ corpus da pesquisa foi constituído por quatro obras de Edgar Morin, sendo três delas pertencentes ao que ele denomina por Trilogia (2000, 2001, 2003) e uma que prolonga a trilogia (2015). A sistematização do conhecimento deu-se por meio das categorias Complementaridade, Prática Pedagógica e Educação. As categorias geraram quadros organizativos que permitem a leitura lienar e transversal, de modo a visibilizar complementarmente as ideias elencadas nas quatro obras. Por fim, construiu-se uma matriz relacional que expressa o movimento de sistematização, por meio de uma composição de elementos teóricos próprios da complexidade que emergiram da análise.

Palavras-chave: Pensamento Complexo. Prática docente. Trilogia. Cognição e aprendizagem. Formação de professores.

\section{Edgar Morin and his trilogy focused on the edu- cational system}

\section{Abstract}

This is a qualitative, descriptive-analytical research, in the bibliographic modality of theoretical nature. Its objective is to offer Basic Education te-

\footnotetext{
* Mestre em Educaçaõ (UFPR). Professora do Ensino Fundamental na Rede Particular de Curitiba, Paraná. ORCID: https:/ / orcid.org/0000-0001-73598742. mbatistella.padilha@gmail.com

** Doutora em Educação Matemática (UNICAMP). Professora na Universidade Federal do Paraná (UFPR). E-mai: ettiene@ufpr.br . ORCID: http://orcid. org/0000-0001-5451-9957
} 
achers and trainers a systematization of knowledge about complexity and complex thought that can help them in their pedagogical practices. The research corpus was composed of four works by Edgar Morin, three of them belonging to what he calls Trilogy $(2000,2001,2003)$ and one which prolongs the trilogy (2015). The systematization of knowledge was done through the categories Complementarity, Pedagogical Practice and Education. The categories generated organizational frameworks that allow reading lienar and transversal, in order to visualize complementarily the ideas listed in the four works.Finally, a relational matrix was constructed that expresses the movement of systematization, by means of a composition of theoretical elements proper to the complexity that emerged from the analysis.

Keywords: Complex Thought. Teaching practice. Trilogy. Cognition and learning. Teacher training.

\section{Edgar Morin y su trilogía centrada en el sistema educativo}

\section{Resumen}

Se trata de una investigación cualitativa, descriptiva-analítica, en la modalidad bibliográfica, de carácter teórico. Tiene como objetivo ofrecer a los Profesores de Educación Básica y a los maestros de profesores una sistematización del conocimiento sobre la complejidad y el pensamiento complejo que pueda ayudarlos en sus prácticas pedagógicas. El corpus de investigación fue constituido por cuatro trabajos de Edgar Morin, tres de los cuales pertenecen a lo que él llama "Trilogía" (2000, 2001, 2003) y uno que amplía la trilogía (2015). La sistematización del conocimiento se realizó mediante las categorías de Complementariedad, Práctica Pedagógica y Educación. Las categorías generaron marcos organizacionales que permiten la lectura lineal y transversal, con el fin de complementar las ideas enumeradas en los cuatro trabajos. Finalmente, se construyó una matriz relacional que expresa el movimiento de sistematización, a través de una composición de elementos teóricos inherentes a la complejidad que emergieron del análisis.

Palabras clave: Pensamiento complejo. Práctica docente. Trilogía. Cognición y aprendizaje. Formación de profesores. 


\section{Introdução}

Compactuamos com os educadores que defendem que a escola necessita de práticas pedagógicas que transcendam a transmissão do conhecimento, que superem a prática didática fragmentada do conhecimento hierarquicamente organizado nos programas escolares, e que considere a multidimensionalidade constitutiva de seus alunos e, por que não, de seus pares. Compactuamos com os que almejam uma educação na perspectiva do pensamento complexo em que a prática didática vise ao desenvolvimento do pensamento estratégico para o enfrentamento crítico das situações que a vida apresenta. Compactuamos com os que pretendem a transcendência da disciplinarização escolar, desenvolvendo práticas conexas, contextualizadas e pertinentes.

A atualidade do pensamento de Edgar Morin encanta educadores que compactuam com a perspectiva apontada. Este artigo está situado no campo educativo escolar. Dirigimo-nos celularmente aos educadores, em uma perspectiva hologramática, que pensa o Homem, o planeta, a preparação para a vida e para o mundo.

Edgar Morin oferece suporte teórico para uma educação escolar que vislumbre o Homem circunstanciado, dialógico, consciente de si e do outro. Uma educação que, em todas as instâncias e circunstâncias, pense o agora como esteio para o amanhã que, ao tornar-se um novo agora, impulsione outros tantos amanhãs quantos a existência de cada um permita viver. Nesse movimento entre diferentes "agoras", está a escola que transversaliza os diferentes tempos. Para Morin, é urgente uma reforma na educação que abra novos caminhos para novas descobertas. Para essa reforma, em meio a um universo de fatores e vetores, é preciso olhar para os professores, para seus modos de pensar e de agir.

Em meio à sua extensa e densa literatura, Morin dedica-se a escrever para o campo educacional. Dedica-lhe uma trilogia composta pelas seguintes obras: "A cabeça bem-feita: repensar a reforma, reformar o pensamento." (MORIN, 2000); "Sete saberes necessários à educação do futuro" (MORIN, 2001); "Educar na era 
planetária: o pensamento complexo como método de aprendizagem no erro e na incerteza humana." (MORIN, 2003). Essa última, que reflete o pensamento complexo como método de aprendizagem no erro e na incerteza humana, publicada em coautoria com Emilio Roger Ciurana e Raúl Domigo Motta. Concordamos com estudiosos da complexidade, como Petraglia, quando consideramos Edgar Morin leitura indispensável para os "[...] que possuem preocupação referente à produção do conhecimento multidimensional, a complexidade do pensamento plural e a consciência reflexiva de si e do mundo, a partir da reflexão e da crítica transformadora." (PETRAGLIA, 2011, p. 14). Por isso, neste artigo, oferecemos uma sistematização de alguns pontos nodais da trilogia que julgamos importantes para a comunidade educativa ${ }^{1}$.

\section{A investigação}

Trata-se de pesquisa qualitativa, descritiva-analítica, bibliográfica, de natureza teórica, com o objetivo de elencar conhecimentos pertencentes às obras que podem auxiliar professores da Educação Básica em suas práticas pedagógicas. Também pretende-se promover a sensibilização dos profeassores para o conhecimento sobre o pensamento complexo. Para tanto, sistematizamos ideias de Morin apresentadas na trilogia em tela, acrescida da obra denominada "Ensinar a viver: manifesto para mudar a educação" (MORIN, 2015). Segundo ele, "Este livro prolonga uma trilogia voltada não apenas para uma reforma de nosso sistema educacional, mas à sua superação, termo que significa não apenas que algo que deve ser ultrapassado deve também ser conservado, mas, também, que tudo o que deve ser conservado deve ser revitalizado". (MORIN, 2015, p. 9). Durante o processo de sistematização, elencamos ideias e conhecimentos que consideramos importantes para a compreensão do pensamento moriniano pela comunidade educativa.

Os conhecimentos foram sistematizados por meio de três categorias: Complementaridade, Prática Docente e Educação. A

Sistematização ampliada encontra-se em Batistella (2018). 
primeira, Complementariedade, devido ao objetivo de identicar conhecimentos que se complementam nas quatro obras, de modo a dar ideia dos seus significados. A segunda, Prática Docente, devido à especificidade da ação didática e a possibilidade da transcendência da disciplinarização escolar. A terceira, Educação, pela amplitude da obra de Morin, pela multidimensionalidade que lhe é inerente, se pensada em uma perpectiva complexa, e pelos objetivos formativos que lhe são intrínsecas.

Os componentes das categorias foram construídos por meio de leitura flutuante das obras, identificação dos constructos teóricos de cada termo em cada obra, leitura para consolidação teórica dos termos, inicialmente focalizada e, na sequência contextual. Os conhecimentos estão sistematizados em quadros que possibilitam leitura linear e transversal. De modo linear, a leitura permite identificar como as ideias nas diferentes obras se complementam. De modo transversal, a leitura permite estabelecer relações entre diferentes conhecimentos.

A seguir, criamos uma Matriz Relacional, por meio da tessitura de um esquema, durante a investigação, que a foi transformando. A ideia da matriz relacional foi de estabelecer um movimento de complementaridade entre as obras pertencentes à trilogia já nominada, acrescida da obra "Ensinar a Viver", buscando uma organização permeada pelas categorias Complementaridade, Prática Pedagógica e Educação. Apropriamos-nos do termo "matriz" para criar uma representação imagética com os elementos teóricos que sistematizamos.

À primeira vista, pode parecer que o termno "matriz" contradiga princípios da complexidade, por ser fixa e pré-determinada. Ledo engano. A ideia de matriz é tão somente organizativa de ideias de Morin que transpassam as obras em análise.

O termo "relacional" lhe dá movimento, possibilita diálogos. Tem duas funções: a) uma é a de constituir-se em um mapa conceitual estilizado, em que pontos de tangência e de interseção visibilizam os conhecimentos, colocando-os em relação; b) outra 
é a de permitir que o leitor estabeleça relações próprias pelo olhar, pelas escolhas que faz.

No campo das ciências exatas, em uma matriz, dados são dispostos em linhas e colunas. Aqui, matriz é uma representação física/imagética que aproxima ideias e permite relacioná-las. Com este sentido, uma matriz linear, aqui se converte em matriz relacional.

As obras não estão ligadas umas às outras. As relações não são fixas, mas construídas pelo leitor, à medida que os elos entre as palavras vão se movimentando. A leitura da matriz segue esse movimento, ininterrupto, de renovação, superação e conservação - características essenciais para o desenvolvimento de um pensamento capaz de religar e reorganizar os saberes.

As obras são representadas por símbolos. O símbolo estrela representa a obra "Os Sete Saberes Necessários à Educação do Futuro"; o triângulo representa a obra "Cabeça Bem-Feita"; o sol representa a obra "Educar na Era Planetária"; o pentágono, a obra "Ensinar a Viver".

Consideramos tais conhecimentos imprescindíveis para a reforma do pensamento proposta por Edgar Morin. Acreditamos que ter consciência deles pode contribuir para uma prática pedagógica que contemple os sujeitos em suas diversas características. Também acreditamos que possam contribuir para um posicionamento pedagógico mais efetivo que potencialize, como movimento formativo, as relações entre indivíduo, sociedade e natureza, ressaltando de suas palavras que "[...] o pensamento é, mais do que nunca, o capital mais precioso para o indivíduo e a sociedade” (MORIN, 2000, p. 18).

\section{A Trilogia}

Do ponto de vista bibliográfico, é importante situar o leitor em relação às obras em análise. Por isso, apresentamos, a seguir, breves notas sobre as obras da trilogia.

A primeira, "Cabeça bem-feita: repensar a reforma. reformar o pensamento" (MORIN, 2000), é uma obra dedicada à educação e ao ensino que aborda sobre um re-pensar da educação. Morin 
indica a necessidade de uma reforma na área educacional. Propõe alguns elementos que poderão auxiliar uma educação que favoreça o pensar aberto e livre.

O pensador constata a "[...] inadequação cada vez mais ampla, profunda e grave entre os saberes separados, fragmentados, compartimentados entre disciplinas, e, por outro lado, realidades ou problemas cada vez mais polidisciplinares, transversais, multidimensionais, transnacionais, globais, planetários." (p. 13). Chama a atenção para o perigo da hiperespecialização que esfacela o conhecimento em fragmentos dissociados do contexto que lhe dá significado. Explica sobre o perigo da expansão descontrolada do saber.

Para a superação desse ensino fragmentado, coloca-nos três desafios à organização do conhecimento: o cultural, o sociológico e o cívico. São três desafios que possibilitam, aos sujeitos, perceber as culturas humanas e científicas como duas esferas interligadas e inseparáveis. Esses desafios também estabelecem uma ligação entre a cultura científica e a cultura das humanidades.

Morin faz uma crítica ao sistema de ensino que isola os objetos, dissocia os problemas, reduz o complexo ao simples. Para ele, é possível situar uma informação em seu contexto, devido a que a ideia de conhecimento pertinente toma corpo em seu pensamento. Para que esse conhecimento se torne pertinente, é necessária uma cabeça "bem-feita", capaz de separar, ligar, relacionar e sintetizar simultaneamente as informações.

Não poderíamos deixar de apresentar o que consideramos uma máxima de Morin que é a lembrança de que "A primeira finalidade do ensino foi formulada por Montaigne: mais vale uma cabeça bem-feita que bem cheia”. (p. 21). Essa cabeça, portanto, tende a estar "[...] apta a organizar os conhecimentos e, com isso, evitar sua acumulação estéril". (p. 24). Vale lembrar que "Depende do pensamento o posicionamento didático dos professores, que podem ter uma ação estanque, fragmentada, engessada pelas limitações disciplinares que regem os currículos escolares" (GUÉRIOS, 2019, p.225), ou ter uma ação que reuslte "em práticas que consideram a 
complexidade da sala de aula e tem a criatividade como propulsora das ações” (p. 229). Daí a aspiração por uma prática didática não fragmentada, que contextualize o conhecimento, que transcenda as amarras da hieraquizarção curricular, que possibilite o desenvolvimento do pensamento estratégico. Como ressaltam Bastos e Petraglia (2019, p.167) "a escola pode ser o lugar do desenvolvimento das múltiplas habilidades criativas tanto individuais quanto grupais".

Morin afirma ainda que uma educação deve favorecer a aptidão natural da mente com auxílio da poesia, da literatura, da filosofia e de outros campos de conhecimento e do viver. Acrescenta dizendo que essa aptidão deve estar ligada à dúvida e à curiosidade dos alunos.

A segunda, "Sete saberes necessários à educação do futuro" (MORIN, 2001), é uma obra que apresenta reflexões para repensar a educação. Morin expõe problemas centrais e fundamentais que são ignorados no campo da educação e apresenta sete saberes indispensáveis para uma educação que situe a condição humana num contexto global e universal. Eis os sete saberes. As cegueiras do conhecimento: o erro e a ilusão, os princípios do conhecimento pertine3nte, ensinar a condição humana, ensinar a identidade terrena, enfrentar as incertezas, ensinar a compreensão e a ética do gênero humano.

Portanto, essa obra pode ser entendida como inspiração para uma mudança de pensamento, e não um manual que se pode aplicar na escola. É uma obra que pode promover uma profunda reflexão dos docentes para que busquem a religação dos saberes, evitando assim promover a separação e valorizar a fragmentação. Importante ressaltar que a $1^{\mathrm{a}}$ e a $2^{\mathrm{a}}$ obra indicam três reformas interdependentes: "[...] reforma do modo de conhecimento, reforma do pensamento e reforma do ensino." (MORIN; CIURANA; MOTTA, 2003, p. 12).

A terceira, "Educar na Era Planetária: o pensamento complexo como método de aprendizagem no erro e na incerteza humana" (MORIN; CIURANA; MOTTA, 2003), alerta para os importantes desafios contemporâneos impostos pela era planetária. Morin explica que a obra tem como objetivo considerar problemas 
de método, conferir sentido à noção de complexidade e esclarecer a noção de era planetária em sua perspectiva histórica e em sua complexidade multidimensional. Com conhecimento sobre o conhecimento dos professores, afirma que muitos deles confundem método com metodologia, termo constitutivo da prática pedagógica por ser da rotina escolar. Aborda sobre método como uma disciplina do pensamento coadjuvante - e por que não estruturante - da elaboração de estratégias cognitivas "[...] situando e contextualizando suas informações, conhecimentos e decisões, tornando-o apto para enfrentar o desafio onipresente da complexidade." (p. 13). De um modo, até certo ponto poético, nos diz que a complexidade é um "método de aprendizagem na errância e na incerteza humanas".

A obra está organizada em três capítulos: o método, a complexidade do pensamento complexo e os desafios da era planetária. No epílogo, explica sobre a missão da educação para a era planetária.

Morin explica que "[...] a complexidade constitui um desafio que a mente deve e pode ultrapassar, apelando a alguns princípios que permitem o exercício de um pensamento complexo", que define como "[...] um estilo de pensamento e de aproximação à realidade. Nesse sentido, ele gera sua própria estratégia inseparável da participação inventiva daqueles que o desenvolvem". (p. 31).

\section{Prolongando a trilogia}

Edgar Morin "prolonga" sua trilogioa com a obra "Ensinar a viver: manifesto para mudar a educação” (2014). Na obra, Morin discute sobre o viver e o ensinar a viver. Faz uma pergunta instigante: O que é viver? Ao que responde: "Viver é uma aventura. Desde a infância, da escola até a adolescência.” (MORIN, 2015, p. 16). E pela vida toda. Para ele, é viver como indivíduo, enfrentando os problemas. É viver como cidadão, pertencente à humanidade. Viver é enfrentar incessantemente o risco de erro, nas escolhas das decisões; é ter necessidade de agir; é conseguir situar qualquer objeto ou acontecimento em seu contexto; é uma aventura que implica incertezas sempre renovadas. 
Para ele, a incerteza é um caminhar no processo do conhecimento. Viver é ter a necessidade de compreender e ser compreendido; é saber que qualquer decisão, qualquer escolha constitui um desafio; é religar os saberes à vida. Morin faz uma crítica à escola que, em momento algum, ensina os sujeitos para a aventura que é viver. "A compreensão humana não é ensinada em parte alguma." (p. 27).

Entre seus ensinamentos, chama-nos atenção, sobremaneira, seu alerta sobre a falta de ensino a respeito da compreensão humana. "Em consequência, o mal da incompreensão arruína nossas vidas, determina os comportamentos aberrantes, as rupturas, os insultos, os sofrimentos" (p. 27). Depreendemos das críticas de Morin à escola que, ao desenvolver um ensino fragmentado, descontextualizado dos condicionantes da própria existência e dissociado do desenvolvimento da compreensão da própria vida, “[...] nossa educação não nos ensina senão muito parcial e insuficientemente a viver, ela se distancia da vida ao ignorar os problemas permanentes do viver" (p. 27).

De fato, é urgente a reforma da educação por ele preconizada, que tem no bem viver a meta maior. Para tanto, a reforma do pensamento se faz mister, sendo que conhecimento do conhecimento e compreensão são molas-mestras que nos aproximam de uma educação na perspectiva do pensamento complexo.

\section{A sistematização da Análise}

Conforme anunciado, o Quadro 1 corresponde à categoria Complementaridade, em que é possível identificar onde os termos se complementam nas quatro obras, conforme diz o próprio nome. Foram construídos termos de referência em relção a determinados conhecimentos, a que chamamos de termos aglutinadores, como se fossem categorias emergentes Para este artigo, selecionamos as seguintes: incerteza, reforma do pensamento, erro e ilusão, conhecimento pertinente, erro na educação, condição humana, fragmentação, viver, identidade terrena e pensamento complexo. $\mathrm{O}$ Quadro 2 corresponde à categoria Prática Docente. O Quadro 3 correponde à categoria Educação. 


\section{Quadro 1 - Complementaridade}

continua

\begin{tabular}{|c|c|c|c|c|}
\hline Termos & $\begin{array}{c}\text { Cabeça Bem-Feita } \\
(2000)\end{array}$ & $\begin{array}{l}\text { Sete Saberes } \\
\quad(2001)\end{array}$ & $\begin{array}{l}\text { Educar na } \\
\text { Era Planetária } \\
(2003)\end{array}$ & $\begin{array}{c}\text { Ensinar a Viver } \\
\text { (2015) }\end{array}$ \\
\hline 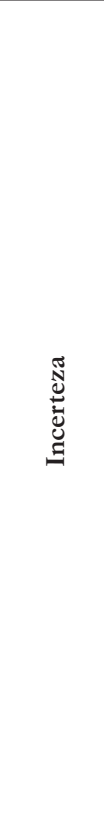 & $\begin{array}{l}\text { Marcada por } 2 \text { in- } \\
\text { certezas: cognitiva e } \\
\text { histórica. } \\
3 \text { viáticos: ecologia } \\
\text { da ação, estratégia e } \\
\text { desafio. } \\
\text { A maior contribuição } \\
\text { do conhecimento } \\
\text { do século XX foi o } \\
\text { conhecimento dos } \\
\text { limites do conheci- } \\
\text { mento. } \\
\text { Conhecer e pensar } \\
\text { não é chegar a uma } \\
\text { verdade absoluta, } \\
\text { mas dialogar com a } \\
\text { incerteza. }\end{array}$ & $\begin{array}{l}\text { Quinto saber } \\
\text { necessário à } \\
\text { educação do } \\
\text { Futuro. } \\
\text { Construímos } \\
\text { a ideia de } \\
\text { que tudo que } \\
\text { é científico, } \\
\text { pertence } \\
\text { às certezas } \\
\text { e verdades } \\
\text { absolutas. } \\
\text { A história } \\
\text { humana foi e } \\
\text { continua a ser } \\
\text { uma aventura } \\
\text { desconhecida. } \\
\text { O futuro } \\
\text { permanece } \\
\text { aberto e im- } \\
\text { previsível. }\end{array}$ & $\begin{array}{l}\text { Em situação } \\
\text { de incerteza, } \\
\text { é preciso uma } \\
\text { atitude estratégi- } \\
\text { ca, ou seja, uma } \\
\text { concepção de } \\
\text { método como } \\
\text { caminho, ensaio, } \\
\text { pois essa concep- } \\
\text { ção permite ao } \\
\text { sujeito aprender, } \\
\text { inventar e criar } \\
\text { "em/ e" durante } \\
\text { seu caminho em } \\
\text { situações incertas. } \\
\text { O método é } \\
\text { obra de um ser } \\
\text { inteligente que } \\
\text { ensaia estratégias } \\
\text { para responder às } \\
\text { incertezas. Nesse } \\
\text { sentido, reduzir o } \\
\text { método a pro- } \\
\text { grama é acreditar } \\
\text { que existe uma } \\
\text { forma a priori } \\
\text { para eliminar a } \\
\text { incerteza. }\end{array}$ & $\begin{array}{l}\text { Não se pode eliminar } \\
\text { a incerteza, pois não } \\
\text { se pode conhecer com } \\
\text { perfeita precisão todas } \\
\text { as interações de um } \\
\text { sistema. A imprevisibi- } \\
\text { lidade reside no pró- } \\
\text { prio cerne do determi- } \\
\text { nismo. A incerteza é } \\
\text { inseparável do viver. O } \\
\text { nascimento dá início a } \\
\text { uma vida, para a qual } \\
\text { nenhuma certeza será } \\
\text { dada, exceto a certeza } \\
\text { da morte. }\end{array}$ \\
\hline 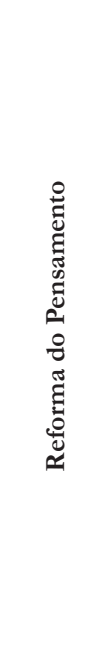 & $\begin{array}{l}\text { Substituir um pen- } \\
\text { samento que isola e } \\
\text { separe por um pensa- } \\
\text { mento que distingua } \\
\text { e una em círculo e } \\
\text { multirreferencial. } \\
\text { O que impede a re- } \\
\text { forma é a rigidez da } \\
\text { máquina educacional, } \\
\text { que é inflexível, fe- } \\
\text { chada e burocrática. }\end{array}$ & $\begin{array}{l}\text { A união dos } \\
\text { sete saberes } \\
\text { em prol de } \\
\text { uma educação } \\
\text { transforma- } \\
\text { dora. } \\
\text { Não é um } \\
\text { manual para } \\
\text { ser aplicado } \\
\text { e sim uma } \\
\text { inspiração } \\
\text { para uma } \\
\text { mudança de } \\
\text { pensamento. }\end{array}$ & $\begin{array}{l}\text { Método, cami- } \\
\text { nho, estratégia e } \\
\text { ensaio contém } \\
\text { um conjunto de } \\
\text { sete princípios } \\
\text { metodológicos } \\
\text { que configuram } \\
\text { um guia para um } \\
\text { pensar complexo. } \\
\text { Pensar que Mé- } \\
\text { todo como cami- } \\
\text { nho não é apenas } \\
\text { para realizar o } \\
\text { que é possível, } \\
\text { mas também } \\
\text { para prensentir o } \\
\text { que é imposível } \\
\text { e que ele não } \\
\text { precede a expe- } \\
\text { riência; o método } \\
\text { emerge durante a } \\
\text { experiência. }\end{array}$ & $\begin{array}{l}\text { Outro modelo de } \\
\text { ciência, um modelo } \\
\text { que religue. } \\
\text { Primeiramente o pro- } \\
\text { fessor precisa aprender } \\
\text { a pensar de maneira } \\
\text { complexa. }\end{array}$ \\
\hline
\end{tabular}




\section{continuação}

\begin{tabular}{|c|c|c|c|c|}
\hline Termos & $\begin{array}{l}\text { Cabeça Bem- } \\
\text { Feita (2000) }\end{array}$ & $\begin{array}{l}7 \text { Saberes } \\
\text { (2001) }\end{array}$ & $\begin{array}{l}\text { Educar na Era } \\
\text { Planetária (2003) }\end{array}$ & $\begin{array}{c}\text { Ensinar a Viver } \\
\text { (2015) }\end{array}$ \\
\hline  & $\begin{array}{l}\text { Especialização que } \\
\text { impede de ver o } \\
\text { global fragmenta } \\
\text { o complexo do } \\
\text { mundo em pedaços } \\
\text { separados. } \\
\text { A hiperespeciali- } \\
\text { zação é incapaz de } \\
\text { pensar a crise, sen- } \\
\text { do uma inteligência } \\
\text { incapaz de perceber } \\
\text { o contexto e o } \\
\text { complexo plane- } \\
\text { tário tonando-se } \\
\text { cega, inconsciente e } \\
\text { irresponsável. }\end{array}$ & $\begin{array}{l}\text { Toda produ- } \\
\text { ção do co- } \\
\text { nhecimento } \\
\text { é passiva de } \\
\text { erro e ilu- } \\
\text { são, pois as } \\
\text { informações } \\
\text { são constru- } \\
\text { ção e re- } \\
\text { construções } \\
\text { cerebrais e } \\
\text { ao tentá-lo } \\
\text { explicar esta- } \\
\text { mos sujeitos } \\
\text { ao erro e } \\
\text { ilusões. }\end{array}$ & $\begin{array}{l}\text { O reconhecimento } \\
\text { do erro favorece } \\
\text { o surgimento da } \\
\text { diversidade e da } \\
\text { possibilidade de } \\
\text { evolução. } \\
\text { O erro é um fenô- } \\
\text { meno humano e } \\
\text { encontra-se ligado } \\
\text { ao surgimento da } \\
\text { linguagem, ou seja, } \\
\text { da palavra e da } \\
\text { ideia. } \\
\text { Erro e verdade } \\
\text { não têm nada de } \\
\text { arbitrário. } \\
\text { Não é possível } \\
\text { conceber o proble- } \\
\text { ma da fecundidade } \\
\text { do erro sem uma } \\
\text { determinda ver- } \\
\text { dade na teoria que } \\
\text { produziu o erro. }\end{array}$ & $\begin{array}{l}\text { Não aceitação pela } \\
\text { ciência do que é } \\
\text { conhecimento huma- } \\
\text { no, seus dispositivos, } \\
\text { suas fraquezas, difi- } \\
\text { culdades, propensões } \\
\text { quanto ao erro e ilu- } \\
\text { são, incapacidade de } \\
\text { estabelecer relações. } \\
\text { Erro comporta misté- } \\
\text { rio e o inesperado. }\end{array}$ \\
\hline 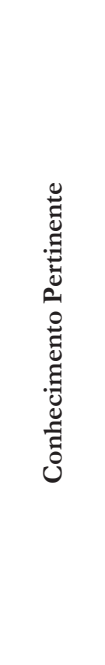 & $\begin{array}{l}\text { Necessário uma } \\
\text { cabeça bem-feita. } \\
\text { Uma cabeça que } \\
\text { seja capaz de es- } \\
\text { tabelecer relações } \\
\text { possíveis. } \\
\text { Precisamos conhe- } \\
\text { cer o que une por } \\
\text { meio da ligação, } \\
\text { separação, análise e } \\
\text { síntese. } \\
\text { É uma necessidade } \\
\text { inserir um } \\
\text { conhecimento } \\
\text { particular em seu } \\
\text { contexto e situá-lo } \\
\text { em seu conjunto. }\end{array}$ & $\begin{array}{l}\text { Lutar contra } \\
\text { a fragmen- } \\
\text { tação } \\
\text { sem deixar } \\
\text { de lado o } \\
\text { contexto, } \\
\text { deve trazer o } \\
\text { todo. } \\
\text { Reconhecer } \\
\text { a relação de } \\
\text { dependên- } \\
\text { cia entre o } \\
\text { contexto e o } \\
\text { global. }\end{array}$ & $\begin{array}{l}\text { Conceber a noção } \\
\text { de método como } \\
\text { caminho, ensaio e } \\
\text { estratégia tornará } \\
\text { o conhecimento } \\
\text { pertinente. } \\
\text { Para elucidar as } \\
\text { circustâncias, para } \\
\text { compreender a } \\
\text { complexidade } \\
\text { humana e o devir } \\
\text { do mundo requer- } \\
\text {-se um pensar } \\
\text { que transcenda a } \\
\text { ordem dos saberes } \\
\text { constituídos e da } \\
\text { trivialidade do dis- } \\
\text { curso acadêmico. }\end{array}$ & $\begin{array}{l}\text { Capacidade de con- } \\
\text { textualizar. } \\
\text { Capacidade de situar } \\
\text { qualquer informação } \\
\text { em seu contexto. } \\
\text { Tornar evidente o } \\
\text { contexto, o global e o } \\
\text { complexo. }\end{array}$ \\
\hline
\end{tabular}




\section{continuação}

\begin{tabular}{|c|c|c|c|c|}
\hline Termos & $\begin{array}{l}\text { Cabeça Bem- } \\
\text { Feita (2000) }\end{array}$ & $\begin{array}{l}7 \text { Saberes } \\
\text { (2001) }\end{array}$ & $\begin{array}{l}\text { Educar na Era } \\
\text { Planetária (2003) }\end{array}$ & $\begin{array}{c}\text { Ensinar a Viver } \\
\text { (2015) }\end{array}$ \\
\hline 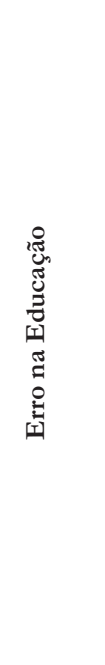 & $\begin{array}{l}\text { O ser humano é } \\
\text { visto como vítima } \\
\text { de grande disjunção } \\
\text { natureza/ cultura } \\
\text { animalidade/ } \\
\text { humanidade, sem- } \\
\text { pre desmembrado } \\
\text { entre sua natureza } \\
\text { de ser vivo estu- } \\
\text { dada pela biologia, } \\
\text { sua natureza física } \\
\text { e social, estudada } \\
\text { pelas ciências } \\
\text { humanas. }\end{array}$ & $\begin{array}{l}\text { Alerta para a } \\
\text { necessidade } \\
\text { de abordar, } \\
\text { na escola, os } \\
\text { sete saberes } \\
\text { para a Edu- } \\
\text { cação. } \\
\text { Saberes in- } \\
\text { dispensáveis } \\
\text { para uma } \\
\text { educação que } \\
\text { situe a condi- } \\
\text { ção humana } \\
\text { em um con- } \\
\text { texto global e } \\
\text { universal. }\end{array}$ & $\begin{array}{l}\text { - Não le- } \\
\text { var em conta que o } \\
\text { método (caminho) } \\
\text { incorpora o erro e } \\
\text { uma visão diferen- } \\
\text { te da verdade. } \\
\text { Não se pode } \\
\text { reduzir o Método/ } \\
\text { caminho a um } \\
\text { programa, pois o } \\
\text { programa, } \\
\text { segundo os auto- } \\
\text { res, é uma técnica } \\
\text { de produção de } \\
\text { conhecimento. }\end{array}$ & $\begin{array}{l}\text { Por toda parte ensi- } \\
\text { nam-se os conheci- } \\
\text { mentos, em nenhum } \\
\text { lugar ensina-se o que } \\
\text { é o conhecimento. } \\
\text { A educação conser- } \\
\text { vadora não fornece } \\
\text { as defesas para se } \\
\text { enfrentar a incerteza } \\
\text { da existência, não } \\
\text { fornece as defesas } \\
\text { contra o erro, a ilusão } \\
\text { e a cegueira. } \\
\text { Não valoriza a preo- } \\
\text { cupação, o questio- } \\
\text { namento e a reflexão } \\
\text { sobre o bem viver. }\end{array}$ \\
\hline$\stackrel{\vec{D}}{\Delta}$ & $\begin{array}{l}\text { Promover uma } \\
\text { transformação no } \\
\text { ser mental de cada } \\
\text { indivíduo para que } \\
\text { possa usar por toda } \\
\text { vida. } \\
\text { O objetivo da edu- } \\
\text { cação é criar no } \\
\text { aluno um estado } \\
\text { interior e profundo, } \\
\text { uma espécie de } \\
\text { polaridade de espíri- } \\
\text { to que o oriente em } \\
\text { um sentido definido } \\
\text { por toda a sua vida. }\end{array}$ & $\begin{array}{l}\text { Saberes es- } \\
\text { senciais para } \\
\text { a vida. } \\
\text { Problemas } \\
\text { centrais que } \\
\text { permanecem } \\
\text { ignorados, } \\
\text { mas essen- } \\
\text { ciais para o } \\
\text { bem viver. } \\
\text { Estar pre- } \\
\text { parado para } \\
\text { o inesperado } \\
\text { que brota } \\
\text { sem parar } \\
\text { durante toda } \\
\text { a nossa vida. }\end{array}$ & $\begin{array}{l}\text { Viver com } \\
\text { compreensão, } \\
\text { solidariedade e } \\
\text { compaixão. } \\
\text { Viver melhor, } \\
\text { sem ser explora- } \\
\text { do, insultado ou } \\
\text { desprezado. } \\
\text { Buscar a plenitude } \\
\text { e completude do } \\
\text { indivíduo, que se } \\
\text { efetiva através da } \\
\text { música, da poesia, } \\
\text { da mística e das } \\
\text { artes em geral. }\end{array}$ & $\begin{array}{l}\text { Enfrentar incessante- } \\
\text { mente o risco de erros } \\
\text { nas escolhas das deci- } \\
\text { sões. } \\
\text { É religar os saberes à } \\
\text { vida. } \\
\text { Aprende-se a viver por } \\
\text { meio dos livros, da poe- } \\
\text { sia, dos encontros. } \\
\text { Viver é viver como } \\
\text { indivíduo, enfrentando } \\
\text { os problemas de sua } \\
\text { vida pessoal, como } \\
\text { cidadão de sua nação, } \\
\text { é viver também em seu } \\
\text { pertencimento ao gêne- } \\
\text { ro humano. } \\
\text { A vida é um tecido mes- } \\
\text { clado de prosa e poesia. }\end{array}$ \\
\hline
\end{tabular}




\begin{tabular}{|c|c|c|c|c|}
\hline Termos & $\begin{array}{l}\text { Cabeça Bem- } \\
\text { Feita (2000) }\end{array}$ & $\begin{array}{l}7 \text { Saberes } \\
\text { (2001) }\end{array}$ & $\begin{array}{l}\text { Educar na Era } \\
\text { Planetária (2003) }\end{array}$ & Ensinar a Viver (2015) \\
\hline 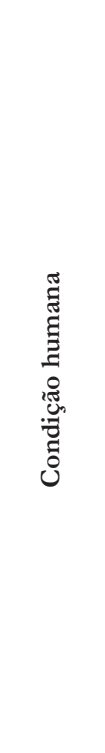 & $\begin{array}{l}\text { Não depende ape- } \\
\text { nas das ciências } \\
\text { humanas. Depende } \\
\text { também das ciências } \\
\text { naturais: Cosmo- } \\
\text { logia, ciências da } \\
\text { Terra e ecologia. } \\
\text { O conceito do } \\
\text { homem tem dupla } \\
\text { entrada: uma bio- } \\
\text { física, uma entrada } \\
\text { psicossociocultural; } \\
\text { duas entradas que } \\
\text { remetem uma à } \\
\text { outra. }\end{array}$ & $\begin{array}{l}\text { Possui rela- } \\
\text { ção com o } \\
\text { universo. } \\
\text { Enraizamen- } \\
\text { to/dese-nrai- } \\
\text { zamento do } \\
\text { ser humano. } \\
\text { A educação } \\
\text { do futuro } \\
\text { deverá ser } \\
\text { o ensino } \\
\text { primeiro e } \\
\text { universal, } \\
\text { centrada na } \\
\text { condição } \\
\text { humana. } \\
\text { Terceiro sa- } \\
\text { ber. Ensinar } \\
\text { a condição } \\
\text { humana. }\end{array}$ & $\begin{array}{l}\text { A relação do } \\
\text { humano com } \\
\text { a natureza e o } \\
\text { planeta não pode } \\
\text { ser concebida de } \\
\text { um modo redutor } \\
\text { nem separado. Se } \\
\text { a relação não for } \\
\text { concebida o ser } \\
\text { humano torna-se } \\
\text { estranho ao pla- } \\
\text { neta. } \\
\text { Para compreender } \\
\text { a condição huma- } \\
\text { na e a condição do } \\
\text { mundo, é preciso } \\
\text { conhecer como, } \\
\text { no nascimento da } \\
\text { história moderna, } \\
\text { a condição do } \\
\text { mundo transfor- } \\
\text { mou-se em era } \\
\text { planetária. }\end{array}$ & $\begin{array}{l}\text { Essencial para o de- } \\
\text { senvolvimento de um } \\
\text { pensamento complexo. } \\
\text { Não é ensinada na } \\
\text { escola. } \\
\text { O humano está disperso, } \\
\text { o conhecimento com- } \\
\text { partimentalizado em } \\
\text { disciplinas. } \\
\text { Ser humano é ser bioló- } \\
\text { gico, psíquico, cultural, } \\
\text { social, histórico. }\end{array}$ \\
\hline
\end{tabular}

\begin{tabular}{|c|c|c|c|c|}
\hline 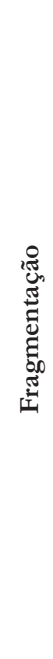 & $\begin{array}{l}\text { Tornam-se invisí- } \\
\text { veis: os conjuntos } \\
\text { complexos, as } \\
\text { interações e retroa- } \\
\text { ções entre parte e } \\
\text { todo, as entidades } \\
\text { multidimensionais e } \\
\text { os problemas es- } \\
\text { senciais. } \\
\text { Impossível apreen- } \\
\text { der “o que é tecido } \\
\text { junto". } \\
\text { Atrofia possibilida- } \\
\text { des de compreensão } \\
\text { e de reflexão, elimi- } \\
\text { nando uma visão a } \\
\text { longo prazo. }\end{array}$ & $\begin{array}{l}\text { A supremacia } \\
\text { do conheci- } \\
\text { mento frag- } \\
\text { mentado de } \\
\text { acordo com } \\
\text { as disciplinas } \\
\text { impede de } \\
\text { operar vín- } \\
\text { culo entre as } \\
\text { partes e a to- } \\
\text { talidade; deve } \\
\text { ser substi- } \\
\text { tuído por } \\
\text { um modo de } \\
\text { conhecimen- } \\
\text { to capaz de } \\
\text { apreender os } \\
\text { objetos em } \\
\text { seu contex- } \\
\text { to, em seu } \\
\text { conjunto. }\end{array}$ & $\begin{array}{l}\text { A inteligência } \\
\text { parcelada, com- } \\
\text { partimentada, } \\
\text { mecanicista, desu- } \\
\text { nida, reducionista } \\
\text { da gestão política } \\
\text { destrói o mundo } \\
\text { complexo em } \\
\text { fragmentos desu- } \\
\text { nidos, fraciona os } \\
\text { problemas, separa } \\
\text { o que está unido, } \\
\text { unidimensionaliza } \\
\text { o multidimen- } \\
\text { sional. }\end{array}$ & $\begin{array}{l}\text { O conhecimento frag- } \\
\text { mentado, monodiscipli- } \\
\text { nar, quantificador leva a } \\
\text { inteligência cega. } \\
\text { Ao parcelar os conheci- } \\
\text { mentos em fragmentos } \\
\text { separados, nossa edu- } \\
\text { cação não nos ensina } \\
\text { senão muito parcial e in- } \\
\text { suficientemente a viver, } \\
\text { ela se distancia da vida } \\
\text { ao ignorar os problemas } \\
\text { permanentes do viver. }\end{array}$ \\
\hline
\end{tabular}




\begin{tabular}{|c|c|c|c|c|}
\hline Termos & $\begin{array}{c}\text { Cabeça Bem- } \\
\text { Feita (2000) }\end{array}$ & $\begin{array}{l}7 \text { Saberes } \\
(2001)\end{array}$ & $\begin{array}{c}\text { Educar na } \\
\text { Era Planetária } \\
\text { (2003) }\end{array}$ & $\begin{array}{c}\text { Ensinar a Viver } \\
\text { (2015) }\end{array}$ \\
\hline 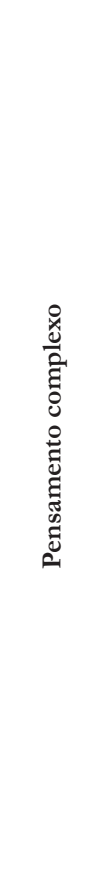 & $\begin{array}{l}\text { Um pensamento } \\
\text { que une, subs- } \\
\text { tituirá a causa- } \\
\text { lidade linear e } \\
\text { unidirecional por } \\
\text { uma causalidade } \\
\text { em círculo e } \\
\text { multirreferencial; } \\
\text { reparará a rigidez } \\
\text { da lógica clássica } \\
\text { pelo diálogo } \\
\text { capaz de conce- } \\
\text { ber noções ao } \\
\text { mesmo tempo } \\
\text { complementares } \\
\text { e antagonistas, } \\
\text { e completará o } \\
\text { conhecimento } \\
\text { da integração } \\
\text { das partes em } \\
\text { um todo, pelo } \\
\text { reconhecimento } \\
\text { da integração } \\
\text { das partes em } \\
\text { um todo, pelo } \\
\text { reconhecimento } \\
\text { da integração do } \\
\text { todo no interior } \\
\text { das partes. }\end{array}$ & $\begin{array}{l}\text { Sete saberes } \\
\text { interligados } \\
\text { que possibili- } \\
\text { tam a religa- } \\
\text { ção de sabe- } \\
\text { res essenciais } \\
\text { à educação. } \\
\text { Os sete } \\
\text { saberes cons- } \\
\text { tituem eixos, } \\
\text { e ao mesmo } \\
\text { tempo, cami- } \\
\text { nhos que se } \\
\text { abrem a todos } \\
\text { que fazem } \\
\text { educação. } \\
\text { Os sete sabe- } \\
\text { res promo- } \\
\text { vem diálogo } \\
\text { criativo com } \\
\text { as dúvidas e } \\
\text { interrogações } \\
\text { do tempo } \\
\text { atual. }\end{array}$ & $\begin{array}{l}\text { Se cria e se re- } \\
\text { cria no próprio } \\
\text { caminhar. } \\
\text { Um pensamen- } \\
\text { to que postula } \\
\text { a dialógica, a } \\
\text { recursividade, a } \\
\text { hologramatici- } \\
\text { dade como seus } \\
\text { princípios mais } \\
\text { pertinentes. } \\
\text { Reconhece o } \\
\text { movimento e a } \\
\text { imprevisão. } \\
\text { Nunca é um } \\
\text { pensamento } \\
\text { completo e está } \\
\text { animado por } \\
\text { tensão. } \\
\text { Não propõe um } \\
\text { programa, mas } \\
\text { um caminho. } \\
\text { Estilo de pen- } \\
\text { samento e de } \\
\text { aproximação à } \\
\text { realidade. }\end{array}$ & $\begin{array}{l}\text { Encontra-se a } \\
\text { possibilidade de } \\
\text { religar. } \\
\text { Reestabelecer o } \\
\text { diálogo entre o } \\
\text { conhecimento. } \\
\text { È preciso tomar } \\
\text { decisões e, } \\
\text { para isso, fazer } \\
\text { escolhas. O que } \\
\text { o pensamento } \\
\text { complexo } \\
\text { ensina é estar } \\
\text { consciente de } \\
\text { que qualque } \\
\text { decisão e } \\
\text { qualquer escolha } \\
\text { constituem um } \\
\text { desafio. }\end{array}$ \\
\hline 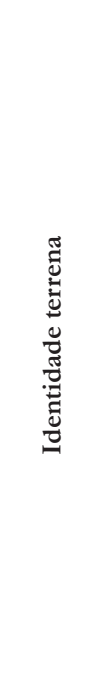 & $\begin{array}{l}\text { Conhecer o } \\
\text { humano não } \\
\text { é separá-lo do } \\
\text { universo, mas } \\
\text { situá-lo no uni- } \\
\text { verso. } \\
\text { Estamos a um só } \\
\text { tempo, dentro e } \\
\text { fora da natureza. } \\
\text { Somos seres } \\
\text { simultaneamente } \\
\text { cósmicos, físicos, } \\
\text { biológicos, } \\
\text { culturais, } \\
\text { cerebrais, } \\
\text { espirituais. So- } \\
\text { mos filhos do } \\
\text { cosmo. }\end{array}$ & $\begin{array}{l}\text { Sustentabili- } \\
\text { dade, pois a } \\
\text { Terra é nossa } \\
\text { casa e preci- } \\
\text { samos cuidar } \\
\text { dela. } \\
\text { O planeta } \\
\text { está em pleno } \\
\text { desenvolvi- } \\
\text { mento. Tal } \\
\text { desenvolvi- } \\
\text { mento ocorre } \\
\text { de forma } \\
\text { desorganiza- } \\
\text { da. È preciso } \\
\text { respeitar os } \\
\text { limites da } \\
\text { nossa Terra. } \\
\text { Diálogo e } \\
\text { compreensão } \\
\text { em prol do } \\
\text { planeta. }\end{array}$ & $\begin{array}{l}\text { O Planeta ainda } \\
\text { não é a Terra } \\
\text { patria. A socie- } \\
\text { dade-mundo } \\
\text { encontra-se em } \\
\text { gestação inaca- } \\
\text { bada, submetida } \\
\text { a forças destru- } \\
\text { tivas/criativase, } \\
\text { talvez, nunca } \\
\text { sera levada a } \\
\text { cabo. } \\
\text { Para compreen- } \\
\text { der a era palane- } \\
\text { tária, é preciso } \\
\text { conceber uma } \\
\text { história geral } \\
\text { da humanidade } \\
\text { que começa } \\
\text { com a diáspo- } \\
\text { ra do Homo } \\
\text { Sapiens por } \\
\text { todo o planeta. }\end{array}$ & $\begin{array}{l}\text { A era planetária } \\
\text { precisa ser ensi- } \\
\text { nada na escola. } \\
\text { Mostrar que vi- } \\
\text { vemos na mesma } \\
\text { comunidade de } \\
\text { destino. } \\
\text { É conveniente } \\
\text { ensinar a história } \\
\text { da era planetária, } \\
\text { que começa com } \\
\text { a comunicação } \\
\text { de todos os } \\
\text { continentes a } \\
\text { partir do século } \\
\text { XVI, e mostrar } \\
\text { as opressões e } \\
\text { dominações que } \\
\text { devastaram a } \\
\text { humanidade. }\end{array}$ \\
\hline
\end{tabular}




\section{Quadro 2 - Prática Docente}

\begin{tabular}{|c|c|c|c|}
\hline Cabeça Bem-Feita (2000) & 7 Saberes (2001) & $\begin{array}{l}\text { Educar na era plan- } \\
\text { etária (2003) }\end{array}$ & $\begin{array}{c}\text { Ensinar a viver } \\
\text { (2015) }\end{array}$ \\
\hline $\begin{array}{l}\text { Diferenciar estratégia e } \\
\text { programa. } \\
\text { Considerar a literatura, poe- } \\
\text { sia, cinema, música como es- } \\
\text { colas de experiência de vida, } \\
\text { ou seja, de descoberta de si } \\
\text { (subjetividade) e da condição } \\
\text { humana favorecendo a cultu- } \\
\text { ra das humanidades. } \\
\text { Reconhecer a multidimen- } \\
\text { sionalidade do ser humano. } \\
\text { Sempre procurar ligações } \\
\text { e interretro-ações entre o } \\
\text { fenômeno e seus contextos, } \\
\text { relações de reciprocidade } \\
\text { entre parte e todo. }\end{array}$ & $\begin{array}{l}\text { Aceitar o novo e o } \\
\text { inesperado. } \\
\text { Considerar a triáde } \\
\text { indivíduo, sociedade e } \\
\text { espécie. } \\
\text { Diálogo e com- } \\
\text { preensão em prol do } \\
\text { desenvolvimento do } \\
\text { planeta. } \\
\text { É preciso ensinar } \\
\text { que o conhecimento } \\
\text { é incerto e que } \\
\text { o conhecimento } \\
\text { científico nunca é } \\
\text { produtor de certezas. }\end{array}$ & $\begin{array}{l}\text { Os seis eixos estraté- } \\
\text { gicos-diretores como } \\
\text { auxílio para organizar } \\
\text { a informação e a } \\
\text { dispersão dos conhe- } \\
\text { cimentos de nosso } \\
\text { meio ambiente para } \\
\text { a elaboração de uma } \\
\text { mundologia cotidiana } \\
\text { encontram-se, por } \\
\text { sua vez, configurados } \\
\text { por um princípio } \\
\text { estratégico funda- } \\
\text { mental: compreender } \\
\text { e sustentar nossas } \\
\text { finalidades terrestres. } \\
\text { Isto é, fortalecer as } \\
\text { atitudes e aptidões } \\
\text { dos homens para } \\
\text { sobrevivência da } \\
\text { espécie humana e } \\
\text { para prosseguimento } \\
\text { da hominização. }\end{array}$ & $\begin{array}{l}\text { Ensinar a compreen- } \\
\text { são do discurso do } \\
\text { outro, suas ideias, sua } \\
\text { visão do mundo. } \\
\text { Ensinar e ética do } \\
\text { diálogo. } \\
\text { Compreender os } \\
\text { problemas sociais. } \\
\text { Preparar os alunos } \\
\text { para enfrentar os } \\
\text { desafios da vida. }\end{array}$ \\
\hline
\end{tabular}

Fonte: Adaptado de Batistella e Guérios (2018)

\section{Quadro 3 - Educação}

\begin{tabular}{|c|c|c|c|}
\hline Cabeça Bem-Feita (2000) & 7 Saberes (2001) & $\begin{array}{l}\text { Educar na era plan- } \\
\text { etária (2003) }\end{array}$ & $\begin{array}{l}\text { Ensinar a viver } \\
(2015)\end{array}$ \\
\hline $\begin{array}{l}\text { Morin aborda um repensar } \\
\text { a educação. Coloca a neces- } \\
\text { sidade de uma reforma na } \\
\text { educação, e aponta a crise no } \\
\text { atual modelo educacional. } \\
\text { Apresenta alguns elementos } \\
\text { que poderão auxiliar um } \\
\text { pensar aberto e livre. Nesta } \\
\text { obra Morin coloca sete prin- } \\
\text { cípios para um pensamento } \\
\text { de união. São eles: } \\
\text { 1. Princípio sistêmico orga- } \\
\text { nizacional; } \\
\text { 2. Hologramático; } \\
\text { 3. Circuito retroativo; } \\
\text { 4. Circuito recursivo; } \\
\text { 5. Autonomia/ dependência; } \\
\text { 6. Dialógico; } \\
\text { 7. Reintrodução do conhe- } \\
\text { cimento em todo conheci- } \\
\text { mento. }\end{array}$ & $\begin{array}{l}\text { São saberes que Morin } \\
\text { coloca como indispen- } \\
\text { sáveis e que são igno- } \\
\text { rados pela educação. } \\
\text { Saberes necessários } \\
\text { para situar a condição } \\
\text { humana num contexto } \\
\text { global e universal. São } \\
\text { eles: } \\
\text { 1. Cegueiras do Conhe- } \\
\text { cimento; } \\
\text { 2. Conhecimento } \\
\text { Pertinente; } \\
\text { 3. Condição Humana; } \\
\text { 4. Identidade Terrena; } \\
\text { 5. Enfrentar a incer- } \\
\text { teza; } \\
\text { 6. Compreensão; } \\
\text { 7. Ética do gênero } \\
\text { humano. }\end{array}$ & $\begin{array}{l}\text { - A educação deve } \\
\text { compreender que a } \\
\text { complexidade humana } \\
\text { mostra um ser biocul- } \\
\text { tural: sapiens/demens. } \\
\text { O principal objetivo } \\
\text { da educação na era } \\
\text { planetária é educar } \\
\text { para o despertar de } \\
\text { uma nova visão de } \\
\text { sociedade e de mundo. }\end{array}$ & $\begin{array}{l}\text { É uma obra que } \\
\text { estende as anteriores. } \\
\text { Aborda o que é viver } \\
\text { num contexto mul- } \\
\text { tidimensional. Aqui } \\
\text { Morin aprofunda } \\
\text { sobre como ensinar } \\
\text { a viver. }\end{array}$ \\
\hline
\end{tabular}

Fonte: Adaptado de Batistella e Guérios (2018). 
Figura 1 - Matriz relacional

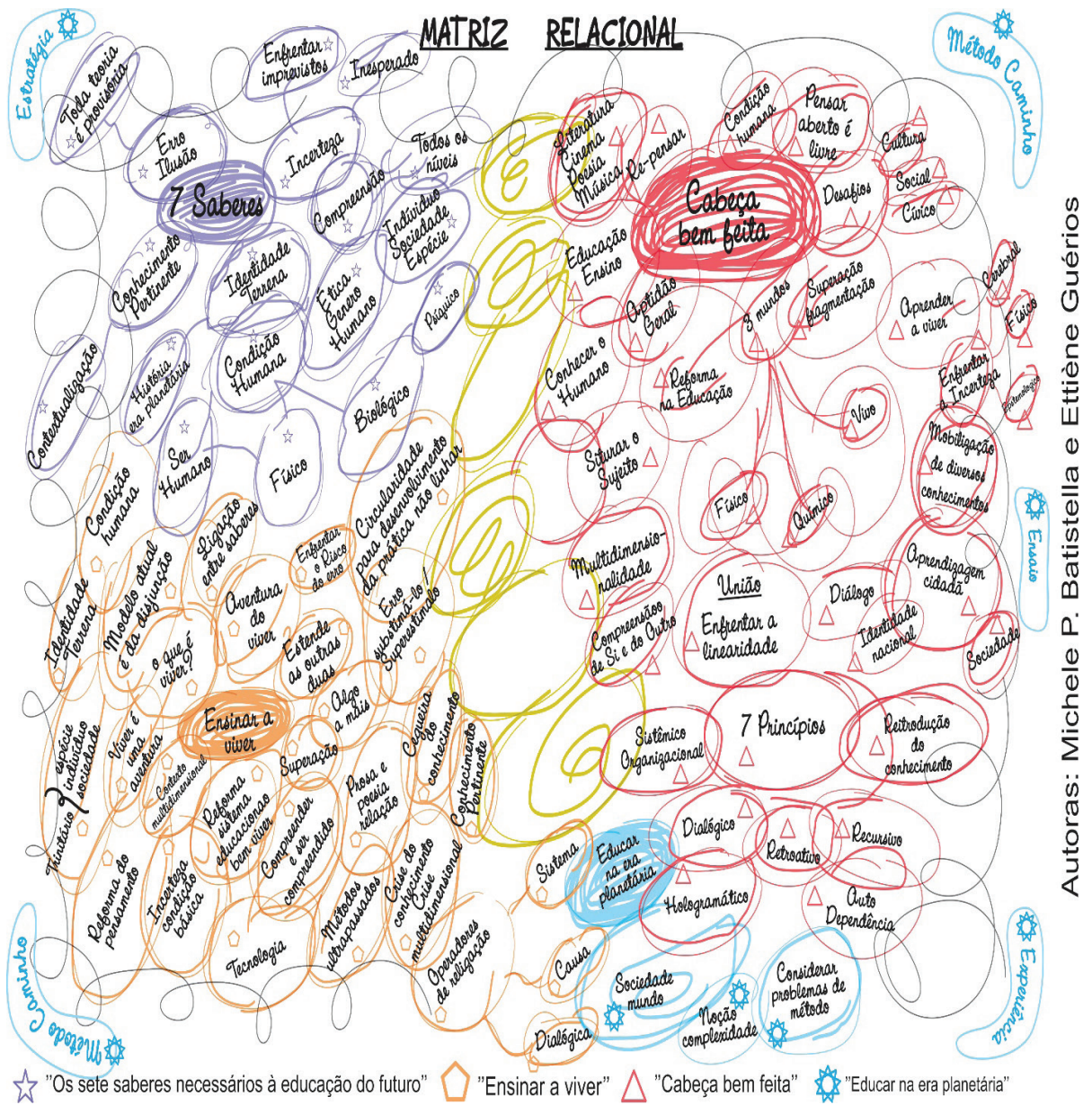

Fonte: Batistella e Guérios (2018, p. 50). 


\section{Considerações}

Acreditamos que a prática docente é um dos mais importantes e centrais problemas que necessitam ser enfrentados se almejamos uma educação na perspectiva do pensamento complexo. Defendemos a urgência de uma reforma de pensamento que leve à reforma da educação. Temos consciência de que a reforma que desejamos não acontecerá em curto prazo, porém é preciso começar a trilhar novos caminhos.

A trilogia de Morin nos faz refletir sobre a importância do papel do professor para a superação de um pensamento redutor e simplificador que implica a busca de uma compreensão aberta aos desafios e problemas da humanidade, bem como as relações entre sociedade, indivíduo, natureza, ética, solidariedade, política, moral, e demais pilares constitutivos do viver. Ele nos mostra a importância da superação da disciplinarização na escola. Afirma que: "A reforma de pensamento conduz a uma reforma de vida que é também necessária para o bem viver.” (MORIN, 2015, p. 136).

Morin (2000) também nos mostra que é preciso pensar diferente, pensar complexo, pensar além, que é preciso transformar o conhecimento da complexidade em pensamento da complexidade (MORIN, 2005). Complementarmente, Guérios acrescenta que "O corolário dessa afirmação é: não basta conhecer. é preciso pensar! articular ideias, criar, transcender ao estabelecido. ou seja, o conhecimento da complexidade se converte[r] em complexidade, em pensamento." (2019, p. 225). Morin nos mostra a importância da superação da disciplinarização na escola sob o ponto de vista da ação didática, ao pensá-la contextualmente; da relação dos alunos com o mundo, ampliando o universo escolar e das relações entre os pares, considerando a multidimensionalidade do espaço educativo.

Afirmamos anteriormente que é preciso olhar para os professores, para seus modos de pensar e de agir. Concluímos que a trilogia voltada ao sistema educacional se constitui no olhar de Edgar Morin aos professores e converte-se em subsídio para auxiliá-los em suas práticas pedagógicas. 


\section{Referências}

BATISTELLA, M. P. A prática Pedagógica na perspectiva do pensamento complexo. 2018. 128f. Dissertação (Mestrado em Educação) - Universidade Federal do Paraná, Curitiba, 2018. Disponível em: https://acervodigital.ufpr.br/handle/1884/58433. Acesso em: 17 jul. 2020.

GUÉRIOS, Ettiène. Contribuições do pensamento complexo para a formação de professores em uma perspectiva transdisciplinar. In: SÁ, Ricardo Antunes de; BEHRENS, Marilda. Aparecida (org.). Teoria da Complexidade: contribuições epistemológicas e metodológicas para uma pedagogia complexa. Curitiba: Appris. 2019, p. 223-236.

MORIN, Edgar. A cabeça bem-feita: repensar a reforma, reformar o pensamento. Tradução de Eloá Jacobina. 7. ed. Rio de Janeiro: Bertrand Brasil, 2000.

MORIN, Edgar. Os sete saberes necessários à educação do futuro. Tradução de Catarina Eleonora F. da Silva e Jeanne Sawaya. 4. ed. São Paulo: Cortez, 2001.

MORIN, Edgar; CIURANA, Emilio Roger; MOT'TA, Raúl Domingo. Educar na Era Planetária: o pensamento complexo como método de aprendizagem no erro e na incerteza humana. Tradução de Sandra Trabucco Valenzuela. São Paulo: Cortez, 2003.

MORIN, Edgar. Ciência com consciência. Tradução de Maria D. Alexandre e Maria Alice Sampaio Dória. 8. ed. São Paulo: Bertrand Brasil, 2005.

MORIN, Edgar. Ensinar a viver: manifesto para mudar a educação. Tradução de Edgard de Assis Carvalho e Mariza Perassi Bosco. Porto Alegre: Sulinas, 2015.

PETRAGLIA, Izabel. Edgar Morin: a educação e a complexidade do ser e do saber. 12. ed. Petrópolis, RJ: Vozes, 2011.

BASTOS, Claudio. PETRAGLIA, Izabel. Morte e a Complexidade Humana. In: SÁ, Ricardo Antunes; BEHRENS, Marilda Aparecida (org.). Teoria da Complexidade: contribuições epistemológicas e metodológicas para uma Pedagogia Complexa. Curitiba: CRV, 2019. p. 155-168. 